\title{
Improved Postprandial Glycemic Control with Faster-Acting Insulin Aspart in Patients with Type 1 Diabetes Using Continuous Subcutaneous Insulin Infusion
}

\author{
Bruce W. Bode, MD, FACE, Joseph A. Johnson, PA-C, ${ }^{1}$ Liselotte Hyveled, MSc, Pharm, MMBA, \\ Søren C. Tamer, $\mathrm{MSc}^{2}$ and Marek Demissie MD, $\mathrm{PhD}^{2}$
}

\begin{abstract}
Background: Faster aspart is insulin aspart (IAsp) in a new formulation, which in continuous subcutaneous insulin infusion (CSII) in subjects with type 1 diabetes has shown a faster onset and offset of glucose-lowering effect than IAsp.

Methods: This double-blind, randomized, crossover active-controlled trial compared 2-h postprandial plasma glucose (PPG) response, following 2 weeks of CSII with faster aspart or IAsp. Primary endpoint: mean change in PPG $2 \mathrm{~h}$ after a standardized meal test $\left(\Delta \mathrm{PG}_{\mathrm{av}, 0-2 \mathrm{~h}}\right)$. Subjects $(n=43)$ had masked continuous glucose monitoring (CGM) throughout.

Results: Faster aspart provided a statistically significantly greater glucose-lowering effect following the meal versus IAsp: $\Delta \mathrm{PG}_{\mathrm{av}, 0-2 \mathrm{~h}}: 3.03 \mathrm{mmol} / \mathrm{L}$ versus $4.02 \mathrm{mmol} / \mathrm{L}(54.68 \mathrm{mg} / \mathrm{dL}$ vs. $72.52 \mathrm{mg} / \mathrm{dL})$; estimated treatment difference (ETD) $[95 \% \mathrm{CI}]:-0.99 \mathrm{mmol} / \mathrm{L}[-1.95 ;-0.03](-17.84 \mathrm{mg} / \mathrm{dL}[-35.21 ;-0.46] ; P=0.044)$. One hour postmeal, PG levels were $-1.64 \mathrm{mmol} / \mathrm{L}(-29.47 \mathrm{mg} / \mathrm{dL})$ lower with faster aspart versus IAsp $(P=0.006)$. Interstitial glucose $(\mathrm{IG})$ profiles supported these findings; the largest differences were observed at breakfast: 9.08 versus $9.56 \mathrm{mmol} / \mathrm{L}(163.57$ vs. $172.19 \mathrm{mg} / \mathrm{dL}$; ETD [95\% CI]: $-0.48 \mathrm{mmol} / \mathrm{L}[-0.97 ; 0.01] ;-8.62 \mathrm{mg} / \mathrm{dL}[-17.49 ; 0.24] ; P=0.057)$. Duration of low IG levels $(\leq 3.9 \mathrm{mmol} / \mathrm{L}[70 \mathrm{mg} / \mathrm{dL}]$ per $24 \mathrm{~h}$ ) was statistically significantly shorter for faster aspart versus IAsp ( 2.03 h vs. 2.45 h; ETD [95\% CI]: $-0.42[-0.72 ;-0.11] ; P=0.008)$. No unexpected safety findings were observed. Conclusions: CSII delivery of faster aspart had a greater glucose-lowering effect than IAsp after a meal test. CGM results recorded throughout all meals supported this finding, with less time spent with low IG levels.
\end{abstract}

Keywords: Continuous glucose monitoring, Continuous subcutaneous insulin infusion, Insulin pump, Meal test, Postprandial plasma glucose, Type 1 diabetes.

\section{Introduction}

A PPROACHING ENDOGENOUS PHYSIOLOGIC insulin secretion around meal times remains a key goal when developing a new mealtime insulin formulation, and limiting postprandial plasma glucose (PPG) excursions is one of the most challenging aspects when attempting to achieve adequate glycemic control for people with diabetes. ${ }^{1}$

The rapid-acting insulin analogs (RAIAs), lispro, aspart, and glulisine, ${ }^{2-4}$ limit PPG excursions more effectively than regular human insulin. ${ }^{5}$ However, several studies have demon- strated that it is necessary to administer RAIAs $15-20 \mathrm{~min}$ before a meal to improve PPG control. ${ }^{1,6,7}$ An injection-meal interval is often used, but this lessens convenience and dosing flexibility for people with diabetes. ${ }^{1}$ While the RAIAs offer a clinical improvement, compared with regular human insulin, these insulin formulations are still absorbed too slowly from the injection site to achieve optimal control of PPG and suppression of hepatic glucose production. ${ }^{8}$

Continuous subcutaneous insulin infusion (CSII) therapy in people with type 1 diabetes is associated with improved $\mathrm{PPG}^{9}$ and overall glycemic control, as well as decreased risk

\footnotetext{
${ }^{1}$ Atlanta Diabetes Associates, Atlanta, Georgia.

${ }^{2}$ Novo Nordisk A/S, Søborg, Denmark.

(C) Bruce W. Bode et al., 2017; Published by Mary Ann Liebert, Inc. This Open Access article is distributed under the terms of the Creative Commons Attribution Noncommercial License (http://creativecommons.org/licenses/by-nc/4.0/) which permits any noncommercial use, distribution, and reproduction in any medium, provided the original author(s) and the source are credited.
} 
of hypoglycemia, ${ }^{10,11}$ and improved quality of life ${ }^{12}$ and user convenience, compared with multiple daily subcutaneous (s.c.) injections. ${ }^{10,13}$ Improvements in the compatibility of RAIAs versus buffered regular human insulin ${ }^{14}$ and developments in sensor and pump technology have contributed to increased use of CSII. $^{15}$ The T1D Exchange clinic registry of 28,000 US citizens with type 1 diabetes reports that $60 \%$ of participants use CSII, which equates to a rise of $4 \%$ over a 15 -month data collection period (commencing in September 2013). ${ }^{16}$

Nevertheless, excessive PPG excursions ( $\geq 10.0 \mathrm{mmol} / \mathrm{L}$ $[180 \mathrm{mg} / \mathrm{dL}])$ remain common with basal-bolus therapy, ${ }^{1,6}$ CSII, ${ }^{17}$ and closed-loop systems. ${ }^{18-20}$ Thus, the need for mealtime insulin with an even faster onset of action than current RAIAs has become evident.

Faster aspart is insulin aspart (IAsp) in a new formulation, containing the excipients: niacinamide (vitamin B3) and L-arginine. Both excipients are well established and listed in the US Food and Drug Administration database of inactive ingredients for injectable drug products (Inactive Ingredient Search for Approved Drug Products); moreover, the excipient concentrations used in the faster aspart formulation are lower than in some products currently approved for use in humans. ${ }^{21}$ Nonclinical data illustrate that the addition of niacinamide promotes the formation of IAsp monomers after s.c. injection, facilitating a more rapid rate of IAsp absorption across the endothelium into the blood. ${ }^{22}$ In a recent CSII study by Heise et al., faster aspart demonstrated an almost threefold higher insulin exposure in the first $30 \mathrm{~min}$ and a greater glucose-lowering effect during the first $2 \mathrm{~h}$ following bolus dosing, compared with IAsp, while total glucoselowering effects between treatments were similar. ${ }^{23}$

The aim of the present exploratory study was to evaluate the efficacy of the ultrafast-acting mealtime insulin faster aspart in comparison with the currently available RAIA IAsp, both delivered through CSII, in subjects with type 1 diabetes.

\section{Methods}

\section{Study design}

This was a randomized, double-blind, three-period, complete crossover trial in subjects with type 1 diabetes comparing pump-infused faster aspart with IAsp.

Trial duration was 9 weeks, comprising a 2-week screening period, three 2-week treatment periods (with no washout period in between), and 1-week follow-up. During the treatment periods, subjects were randomly assigned (1:1:1) to receive one or two formulations of faster aspart or IAsp.

Although the study investigated two separate formulations of faster aspart, one is no longer being investigated in clinical studies, so only data for the faster aspart formulation investigated in Phase 3 clinical trials are presented in this article.

The trial was conducted in accordance with the Declaration of Helsinki ${ }^{24}$ and the International Conference on Harmonisation Good Clinical Practice Guidelines. ${ }^{25}$ Written informed consent was obtained from subjects before studyspecific procedures were performed. The trial was registered with ClinicalTrials.gov (NCT01682902).

\section{Patient population}

Individuals were enrolled at Atlanta Diabetes Associates, Atlanta, GA. Eligible subjects were adults $\geq 18$ years of age with type 1 diabetes $\left(\mathrm{HbA}_{1 \mathrm{c}} \leq 9.0 \%\right.$ [ $\left.\left.\leq 75 \mathrm{mmol} / \mathrm{mol}\right]\right)$ for $\geq 12$ months before inclusion in the trial and a BMI of $\leq 35.0 \mathrm{~kg} / \mathrm{m}^{2}$ and who had been treated with an insulin analog by CSII for $\geq 3$ months before the screening visit. Subjects were required to have used a MiniMed Paradigm ${ }^{\circledR}$ pump $(515 / 715,522 / 722$ or 523/723; Medtronic, Northridge, CA) and Quick-set ${ }^{\circledR}$ or Silhouette ${ }^{\circledR}$ infusion sets (Medtronic) within the previous 6 months, before the screening visit, and to remain on their own pump during the trial. Subjects were required to use the bolus calculator in the CSII set and be willing to perform carbohydrate counting and produce self-monitored plasma glucose (SMPG) profiles. All subjects consented to use only the masked continuous glucose monitoring (CGM) device (Dexcom G4 ${ }^{\circledR}$ PLATINUM; Dexcom, Inc., San Diego, CA) during the trial period.

\section{Insulin administration}

Faster aspart and IAsp (100 U/mL; Novo Nordisk, Bagsværd, Denmark) were provided in $3-\mathrm{mL}$ Penfill ${ }^{\circledR}$ cartridges (Novo Nordisk) that were used to fill the pump reservoirs. Infusion sites were rotated and all subjects were instructed to change the infusion set and reservoirs every $72 \mathrm{~h}$.

\section{Optimization of insulin dose}

Insulin dose adjustments were made on the basis of masked CGM data during contact with the investigator (four contacts were made in the 2 weeks before each site visit and standardized meal test). The basal rate of infusion, insulin-tocarbohydrate ratio (ICR), and insulin sensitivity factor (ISF) were established in the first week of each treatment period; any necessary minor adjustments were made during the second week at the discretion of the investigator. After each meal test, pump insulin delivery parameters (basal rate, ICR, and ISF) were reset to baseline.

Each bolus dose was established by the subject using the pump bolus calculator (under supervision of the investigator) based on the current preprandial SMPG value and the carbohydrate content of the next meal to be consumed. Adjustments were to be made mainly to the bolus dose in the second week. Subjects were encouraged to count carbohydrates accurately. In each subject, the aim was to meet the following glycemic targets: preprandial and bedtime plasma glucose (PG) $5.0 \mathrm{mmol} / \mathrm{L}$ (90 mg/dL) and 2-h PPG $7.8 \mathrm{mmol} / \mathrm{L}(140 \mathrm{mg} / \mathrm{dL})$.

\section{Meal test}

The meal test was performed on day 14 of each treatment period; subjects were required to fast $(\geq 8 \mathrm{~h})$ and to refrain from using a correction dose $(\geq 4 \mathrm{~h})$ before the site visit, while maintaining a fasting plasma glucose target level of 4.0$7.7 \mathrm{mmol} / \mathrm{L}(72-140 \mathrm{mg} / \mathrm{dL})$. If the subject was not eligible for the meal test on day 14 (see Supplementary Appendix for eligibility criteria; Supplementary Data are available online at www.liebertpub.com/dia), the test was rescheduled within the visit window (and before entering the next 2-week treatment period). Subjects used the bolus calculator in their CSII set to determine each bolus insulin dose (based on meal carbohydrate content and preprandial PG value) under supervision of the investigator. The start of bolus infusion was defined as time point 0 . A standardized liquid meal (BOOST ${ }^{\circledR}$ Nestlé/ Novartis Medical Nutrition, 20 fl. oz. [ $592 \mathrm{~mL}$ ], $600 \mathrm{kcal}$, 
macronutrient content: $102.5 \mathrm{~g}$ [67\%] carbohydrate; $25.0 \mathrm{~g}$ [17\%] protein; and $10.0 \mathrm{~g}$ [16\%] fat) was served immediately after the bolus dose infusion and consumed by the subject, ideally within $8 \mathrm{~min}$. Blood samples for the analysis of PG were taken at intervals from -60 to 240 min after the bolus insulin dose and analyzed at a central laboratory. The total duration of the meal test was expected to be 5-6h.

\section{Fructosamine}

Blood samples drawn at randomization, and at each meal test visit to site, were used to determine serum fructosamine levels.

\section{Self-monitored $P G$}

CGM was performed throughout the trial (see Supplementary Appendix for further information). Subjects were supplied with an Abbott Freestyle Lite (Abbott, Berkshire, United Kingdom) glucose meter and instructions on how to use the device, including how to perform regular calibration. SMPG values (7-7-9-point profiles) were recorded at randomization and twice during each 2 -week treatment period (see Supplementary Appendix for further information).

\section{Pump compatibility}

Subjects were instructed to change their infusion set and reservoir at the same time (preferably early in the day) and according to the manufacturer's instructions at least every $72 \mathrm{~h}$, or sooner if there was any sign of occlusion or leakage, and the day before the next visit. Subjects recorded the time and date of change, the reason for changing (whether routine or other event [e.g., suspicion of occlusions, leakage, or hyperglycemic episode], and to note if there was any macroscopic change in the insulin solution (e.g., color change or particle/crystal formation).

During visits $3,7,11$, and 15 , subjects changed their infusion set and reservoir under the supervision of the investigator (due to change of trial product), and the investigator evaluated the infusion sets macroscopically for any color changes or particle/crystal formation. In case of any findings, the infusion set and reservoir were sent to Novo Nordisk for macroscopic and microscopic confirmation.

\section{Study endpoints}

Primary endpoint. The primary endpoint was the mean change (increment) in PG concentration from 0 to $2 \mathrm{~h}$ $\left(\Delta \mathrm{PG}_{\mathrm{av}, 0-2 \mathrm{~h}}\right)$ following administration of a standardized meal after 2 weeks of CSII treatment.

Secondary endpoints. Secondary endpoints relating to the meal test included mean change (increment) in PG concentration from 0 to $1 \mathrm{~h}\left(\Delta \mathrm{PG}_{\mathrm{av}, 0-1 \mathrm{~h}}\right)$ and $\mathrm{PG}$ concentration at 1 and $2 \mathrm{~h}\left(\mathrm{PG}_{1 \mathrm{~h}}\right.$ and $\left.\mathrm{PG}_{2 \mathrm{~h}}\right)$. Secondary endpoints included fructosamine levels (central laboratory) after each 2-week treatment period and those derived through CGM (for breakfast, lunch, and dinner separately and after all meals), relating to the interstitial glucose (IG) profile characteristics, which consisted of mean change (increment) in IG within $4 \mathrm{~h}$ of a meal (1- and 2-h values only are provided in this article); mean and peak IG within $4 \mathrm{~h}$ of a meal; mean IG profile over 2 weeks of treatment; and any time spent with low IG levels (defined as $<2.5 \mathrm{mmol} / \mathrm{L}$ [ $45 \mathrm{mg} / \mathrm{dL}],<3.0 \mathrm{mmol} / \mathrm{L}$ [54 mg/ $\mathrm{dL}],<3.5 \mathrm{mmol} / \mathrm{L}[63 \mathrm{mg} / \mathrm{dL}]$, or $\leq 3.9 \mathrm{mmol} / \mathrm{L}[70 \mathrm{mg} / \mathrm{dL}])$ or high IG levels (defined as either $\geq 10.0 \mathrm{mmol} / \mathrm{L}[180 \mathrm{mg}$ / $\mathrm{dL}]$ or $>12.0 \mathrm{mmol} / \mathrm{L}$ [216 mg/dL]) over a 24 -h period.

Insulin dose (total, basal, and meal insulin dose) was measured over each 2-week treatment period.

\section{Safety}

Treatment-emergent adverse events (TEAEs), including local tolerability at the infusion site, changes in physical examination, electrocardiogram, and vital signs, were assessed as part of the safety analysis. For each treatment period, an event was categorized as a TEAE if it occurred on or after exposure to the randomized treatment, although no later than 7 days after the last day of randomized treatment. Owing to the absence of a washout period between treatments, TEAEs were assigned to the latest treatment given after crossover.

The number of hypoglycemic episodes was also assessed. A hypoglycemic episode was considered as treatment emergent only if the onset occurred no later than 1 day after administration of the trial product. Hypoglycemic episodes were categorized according to both the American Diabetes Association (ADA) definition ${ }^{26}$ and an additional definition for minor hypoglycemic episodes - that is, any $\mathrm{PG}<3.1 \mathrm{mmol} / \mathrm{L}$ $(56 \mathrm{mg} / \mathrm{dL})$ with symptoms consistent with hypoglycemia, where the subject did not require assistance, or any asymptomatic $\mathrm{PG}$ value $<3.1 \mathrm{mmol} / \mathrm{L}(56 \mathrm{mg} / \mathrm{dL})$.

\section{Pump-related endpoints}

The number of episodes of infusion set occlusions during each 2-week treatment period was assessed.

\section{Statistical methods}

All efficacy endpoints were summarized and analyzed using the full analysis set (FAS), which included all randomized subjects.

All exposed subjects were included in the FAS and the safety analysis set (SAS; all subjects receiving $\geq 1$ dose of the investigational product or its comparator) as treated.

The primary endpoint, $\Delta \mathrm{PG}_{\mathrm{av}, 0-2 \mathrm{~h}}$, was calculated as $\mathrm{AUC}_{\mathrm{PG}, 0-2 \mathrm{~h}} / 2 \mathrm{~h}-\mathrm{PG}_{\text {Pre-dose }}$, where $\mathrm{AUC}_{\mathrm{PG}, 0-2 \mathrm{~h}}$ was the area under the PG concentration-time profile between 0 and $2 \mathrm{~h}$ and $\mathrm{PG}_{\text {Pre-dose }}$ was the PG concentration immediately before administration of trial product. This and all other area under the curve (AUC) values were calculated using the trapezoidal technique. $\Delta \mathrm{PG}_{\mathrm{av}, 0-2 \mathrm{~h}}$ was compared between faster aspart and IAsp with a linear mixed model, with treatment and period as fixed factors, PG level before administration as a covariate, and subject as a random effect. $\Delta \mathrm{PG}_{\mathrm{av}, 0-1 \mathrm{~h}}$ was derived and analyzed in the same way as the primary endpoint. $\mathrm{PG}_{1 \mathrm{~h}}$ and $\mathrm{PG}_{2 \mathrm{~h}}$, and serum fructosamine after 2 weeks of treatment, were analyzed using the same model used for the primary endpoint.

The mean IG level of a profile was derived from the AUC using all available IG measurements and divided by the time period during which the IG measurements were taken. All secondary endpoints derived through CGM and related to IG profile characteristics and duration of low or high IG values were analyzed using a mixed model with treatment and period as fixed factors and subject as a random effect. 
PG values obtained from the 7-7-9-point SMPG profile and insulin doses collected during the trial were summarized using descriptive statistics.

TEAEs and treatment-emergent hypoglycemic episodes are presented in terms of the number (and percentage) of subjects with at least one event, number of events, and rate (per exposure day).

The rate of suspected infusion set occlusions is presented in terms of events per exposure day.

\section{Results}

\section{Subjects}

Baseline characteristics are shown in Table 1. In total, 43 subjects were randomized and exposed to trial product (FAS and SAS); one subject withdrew during the third treatment period due to noncompliance with the protocol. One of the 42 remaining subjects received faster aspart (data not shown) instead of IAsp for one full treatment period and therefore completed two periods on the same treatment.

\section{Meal test}

After 2 weeks of treatment, faster aspart had a statistically significantly greater glucose-lowering effect than IAsp, during the $2 \mathrm{~h}$ after administration of the standardized meal $\left(\triangle \mathrm{PG}_{\mathrm{av}, 0-2 \mathrm{~h}}\right.$, estimated treatment difference [ETD; $\left.95 \% \mathrm{CI}\right]$ : $-0.99 \mathrm{mmol} / \mathrm{L}[-1.95 ;-0.03] ;-17.84 \mathrm{mg} / \mathrm{dL}[-35.21 ;-0.46]$; $P=0.044$; Fig. 1; Table 2). The glucose-lowering effect within $1 \mathrm{~h}\left(\Delta \mathrm{PG}_{\mathrm{av}, 0-1 \mathrm{~h}}\right)$ for faster aspart was in line with the findings for the primary endpoint, but did not reach statistical significance; however, $\mathrm{PG}$ concentration values for faster aspart were statistically significantly lower after $1 \mathrm{~h}\left(\mathrm{PG}_{1 \mathrm{~h}}\right)$ compared with IAsp (Table 2). Similar results were obtained for PG concentration at $2 \mathrm{~h}\left(\mathrm{PG}_{2 \mathrm{~h}}\right)$, which remained lower with faster aspart than with IAsp, although the difference between the two

\section{Table 1. Baseline Characteristics}

\begin{tabular}{lc}
\hline Parameter & $\begin{array}{c}\text { Adults with type 1 } \\
\text { diabetes }(\mathrm{N}=43)\end{array}$ \\
\hline Age, years & $48.0(13.4)$ \\
Gender, $n(\%)$ & \\
$\quad$ Male & $22(51)$ \\
Female & $21(49)$ \\
Race, $n(\%)$ & \\
White & $38(88)$ \\
Black or African American & $3(7)$ \\
Asian non-Indian & $1(2)$ \\
Other & $1(2)$ \\
BMI, kg/m & $27.0(3.6)$ \\
Duration of diabetes, years & $24.2(10.4)$ \\
HbA $A_{1 \mathrm{c}}(\%)$ & $7.5(0.8)$ \\
HbA $(\mathrm{mmol} / \mathrm{mol})$ & $58.5(6.2)$ \\
FPG plasma (mmol/L) & $9.7(3.14)$ \\
FPG plasma (mg/dL) & $175.5(56.5)$ \\
Fructosamine serum $(\mu \mathrm{mol} / \mathrm{L})$ & $321.5(40.6)$ \\
Fructosamine serum $(\mathrm{mg} / \mathrm{dL})$ & $5.8(0.73)$ \\
\hline
\end{tabular}

Values are mean (SD) unless otherwise stated.

BMI, body-mass index; FPG, fasting plasma glucose; $\mathrm{HbA}_{1 \mathrm{c}}$, glycosylated hemoglobin; SD, standard deviation. treatments at this later time point was not statistically significant (Table 2).

The consumption of six meal tests while being treated with faster aspart $(n=1)$ or IAsp $(n=5)$ was delayed between 1 and $5 \mathrm{~min}$; however, the profiles from these subjects were still included in meal test analyses. Eight subjects received fewer than the planned $600 \mathrm{kcal}$ and one subject received the IAsp dose after the start of the meal in the meal test. The profiles from these subjects were excluded from meal test analyses.

\section{Fructosamine}

Mean serum fructosamine levels after 2 weeks of treatment were lower with faster aspart than with IAsp (Supplementary Table S1), but the difference between treatments was not statistically significant (ETD [95\% CI]: $7.31 \mathrm{Umol} / \mathrm{L}$ [-0.93; 15.56]; $P=0.081)$.

\section{Continuous glucose monitoring}

Over 2 weeks of treatment, considering all meals together, mean prandial IG increments were statistically significantly smaller for faster aspart than IAsp, driven by differences at breakfast (the difference between treatments at lunch and dinner did not reach statistical significance; Fig. 2A). There was no difference between faster aspart and IAsp in terms of mean postprandial ( $0-4 \mathrm{~h})$ IG values and peak IG values over 2 weeks of treatment (Fig. 2B).

The difference in the mean of the IG profile over 2 weeks of treatment between faster aspart and IAsp did not reach statistical significance (data not shown). The duration of low IG levels was shorter with faster aspart than with IAsp, with differences of $<3.5$ and $\leq 3.9 \mathrm{mmol} / \mathrm{L}(<63$ and $\leq 70 \mathrm{mg} / \mathrm{dL})$ per $24 \mathrm{~h}$ reaching statistical significance (Fig. 2C). A similar trend was shown for duration of low IG levels of $<2.5$ and $<3.0 \mathrm{mmol} / \mathrm{L}(<45$ and $\leq 54 \mathrm{mg} / \mathrm{dL})$ per $24 \mathrm{~h}$, although the treatment differences between faster aspart and IAsp were not statistically significant. The duration of high IG levels of $\geq 10.0 \mathrm{mmol} / \mathrm{L}(180 \mathrm{mg} / \mathrm{dL})$ and $>12.0 \mathrm{mmol} / \mathrm{L}(216 \mathrm{mg} / \mathrm{dL})$ per $24 \mathrm{~h}$ was not statistically significantly different between the two groups (Fig. 2D).

\section{Self-monitored $P G$}

After 1 week of CSII treatment, the mean PG values from the 7-7-9-point SMPG profile with faster aspart were similar to those with IAsp for most time points (Supplementary Table S2). However, higher values were observed for faster aspart versus IAsp after 2 weeks of CSII treatment (Supplementary Table S2).

\section{Insulin dosing}

The daily bolus, basal, and total doses of insulin (as well as insulin delivery parameters; data not shown) were similar between faster aspart and IAsp (Supplementary Table S3).

\section{Safety}

Overall, a slightly higher rate of TEAEs was reported with faster aspart (38 [88.4\%] of subjects; 0.37 events per day of exposure) than with IAsp (33 [78.6\%] of subjects; 0.29 events per day of exposure; Supplementary Table S4), driven mainly by hyperglycemic episodes; there were no serious adverse events. The rate of overall treatment-emergent hypoglycemic events $(\leq 3.9 \mathrm{mmol} / \mathrm{L}[70 \mathrm{mg} / \mathrm{dL}])^{26}$ per exposure day was 
FIG. 1. Mean baseline-adjusted (A) and actual (B) PG levels over time following infusion with faster aspart or IAsp. Error bars represent standard error of the mean; faster aspart, fasteracting insulin aspart; IAsp, insulin aspart; PG, plasma glucose.

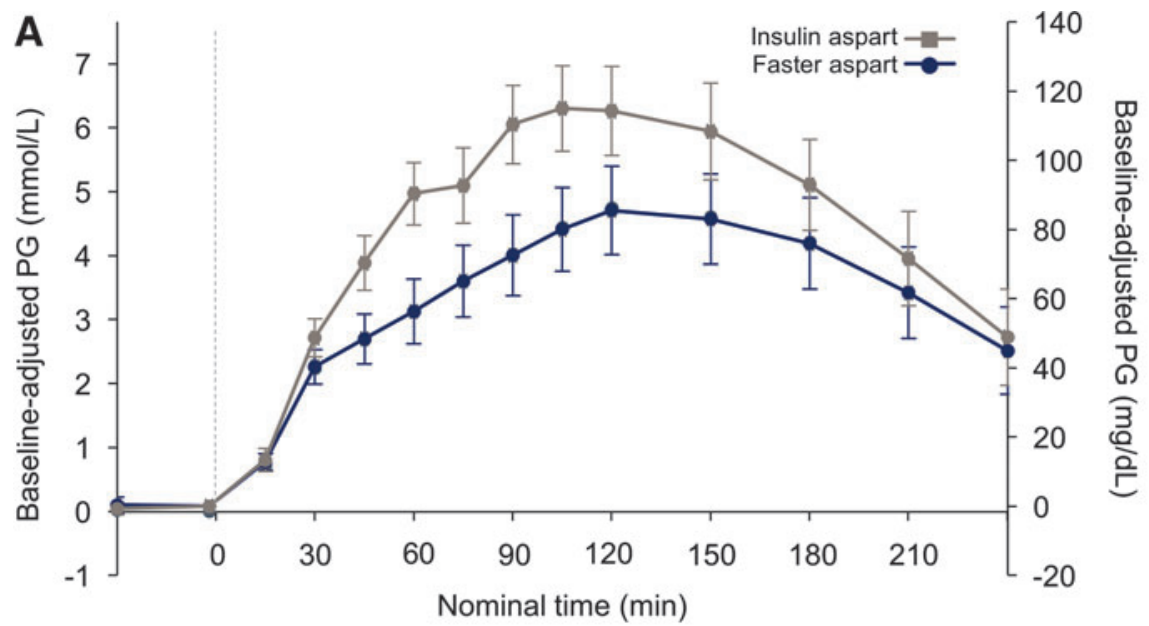

B

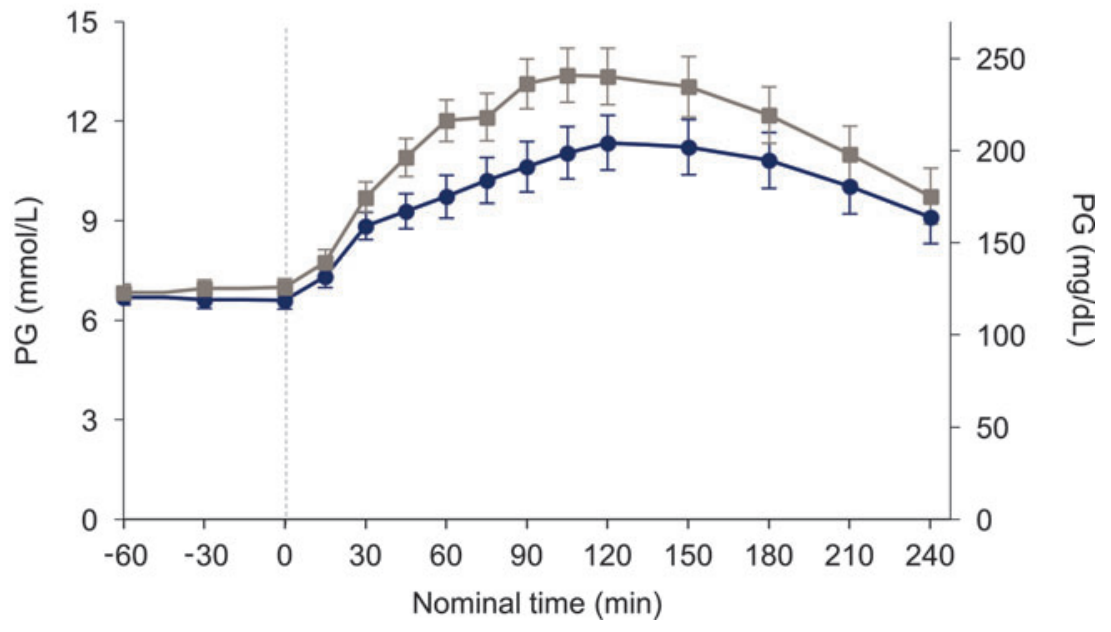

0.87 with faster aspart and 0.97 with IAsp (Supplementary Table S4). The rate of documented symptomatic episodes $\left(\leq 3.9 \mathrm{mmol} / \mathrm{L}\left[70 \mathrm{mg} / \mathrm{dL}^{26}\right]\right)$ per exposure day was 0.45 with faster aspart and 0.55 with IAsp (Supplementary Table S4). No severe hypoglycemic episodes ${ }^{26}$ were reported in either group; the rate of minor hypoglycemic episodes $(<3.1 \mathrm{mmol} /$ L [56 mg/dL]; Supplementary Table S3) was similar between the treatments (Supplementary Table S4).

One infusion site reaction (infusion site pain) was reported for IAsp; one infusion site hematoma and one injection site nodule were reported for faster aspart, both of which disappeared after 10 days.

Changes in measurements related to physical examination, electrocardiogram, and vital signs were similar between faster aspart and IAsp.

\section{Pump compatibility}

There were 0.021 events per exposure day of suspicion of occlusion reported in the infusion sets with both faster aspart

Table 2. Meal Test Results for Faster Aspart and Insulin Aspart

\begin{tabular}{lcccc}
\hline & Faster aspart LSMean & IAsp LSMean & Treatment difference $[95 \%$ CI] & $\mathrm{P}$ \\
\hline$\Delta \mathrm{PG}_{\mathrm{av}, 0-2 \mathrm{~h}}(\mathrm{mmol} / \mathrm{L})$ & 3.03 & 4.02 & $-0.99[-1.95 ;-0.03]$ & 0.044 \\
$\Delta \mathrm{PG}_{\mathrm{av}, 0-2 \mathrm{~h}}(\mathrm{mg} / \mathrm{dL})$ & 54.68 & 72.52 & $-17.84[-35.21 ;-0.46]$ & \\
$\Delta \mathrm{PG}_{\mathrm{av}, 0-1 \mathrm{~h}}(\mathrm{mmol} / \mathrm{L})$ & 1.89 & 2.39 & $-0.50[-1.07 ; 0.07]$ & 0.084 \\
$\Delta \mathrm{PG}_{\mathrm{av}, 0-1 \mathrm{~h}}(\mathrm{mg} / \mathrm{dL})$ & 34.13 & 43.14 & $-9.01[-19.28 ; 1.26]$ & 0.006 \\
$\mathrm{PG}_{\mathrm{hh}}(\mathrm{mmol} / \mathrm{L})$ & 10.05 & 11.68 & $-1.64[-2.79 ;-0.48]$ & 0.168 \\
$\mathrm{PG}_{1 \mathrm{~h}}(\mathrm{mg} / \mathrm{dL})$ & 181.09 & 210.56 & $-29.47[-50.23 ;-8.71]$ & \\
$\mathrm{PG}_{2 \mathrm{~h}}(\mathrm{mmol} / \mathrm{L})$ & 11.71 & 12.93 & $-1.22[-2.98 ; 0.53]$ & \\
$\mathrm{PG}_{2 \mathrm{~h}}(\mathrm{mg} / \mathrm{dL})$ & 211.01 & 233.07 & $-22.06[-53.64 ; 9.52]$ & \\
\hline
\end{tabular}

$\Delta \mathrm{PG}_{\mathrm{av}, 0-2 \mathrm{~h}}$ was calculated as $\mathrm{AUC}_{\mathrm{PG}, 0-2 \mathrm{~h}} / 2 \mathrm{~h}-\mathrm{PG}_{\text {Pre-dose }}$ where $\mathrm{AUC}_{\mathrm{PG}, 0-2 \mathrm{~h}}$ was the area under the PG concentration-time profile based on observed values and actual measurement times in relation to time of injection between 0 and $2 \mathrm{~h}$.

AUC, area under the curve; faster aspart, faster-acting insulin aspart; IAsp, insulin aspart; LS, least squares; PG, plasma glucose. 

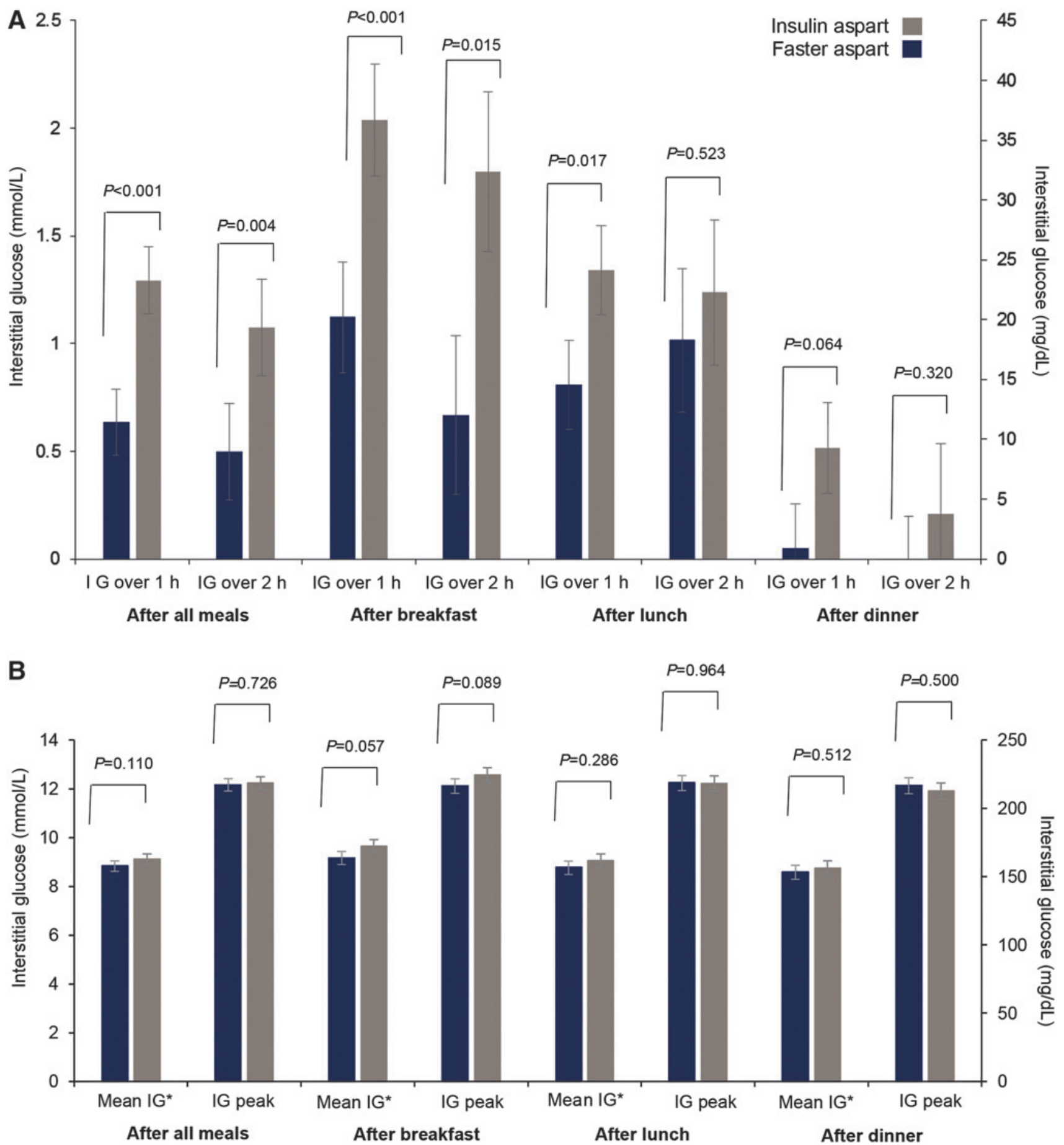

FIG. 2. IG profile characteristics: (A) Mean change (increment) in IG with faster aspart and IAsp at 1 and $2 \mathrm{~h}$ following a meal over 2 weeks of treatment; (B) Mean postprandial $(0-4 \mathrm{~h})$ and peak IG values over 2 weeks of treatment; (C) Duration of low IG levels per $24 \mathrm{~h}$; (D) Duration of high IG levels per $24 \mathrm{~h}$. ${ }^{*} 0-4 \mathrm{~h}$. Error bars represent standard error of the mean. IG, interstitial glucose.

and IAsp, which caused a change of infusion set in addition to routine changes.

\section{Conclusions}

CSII delivery of faster aspart provided a statistically significantly greater glucose-lowering effect than IAsp following a standardized meal test, a finding supported by IG profiles throughout all regular meals during the 2 weeks of each treatment period, where the largest differences occurred at breakfast.

The primary endpoint of the study - mean reduction in PG concentration in the first $2 \mathrm{~h}$ following administration of a standardized meal-was $\sim 25 \%$ greater with faster aspart than with IAsp. In line with this result, PG values at $1 \mathrm{~h}$ after the meal were also statistically significantly lower with faster aspart than with IAsp. 

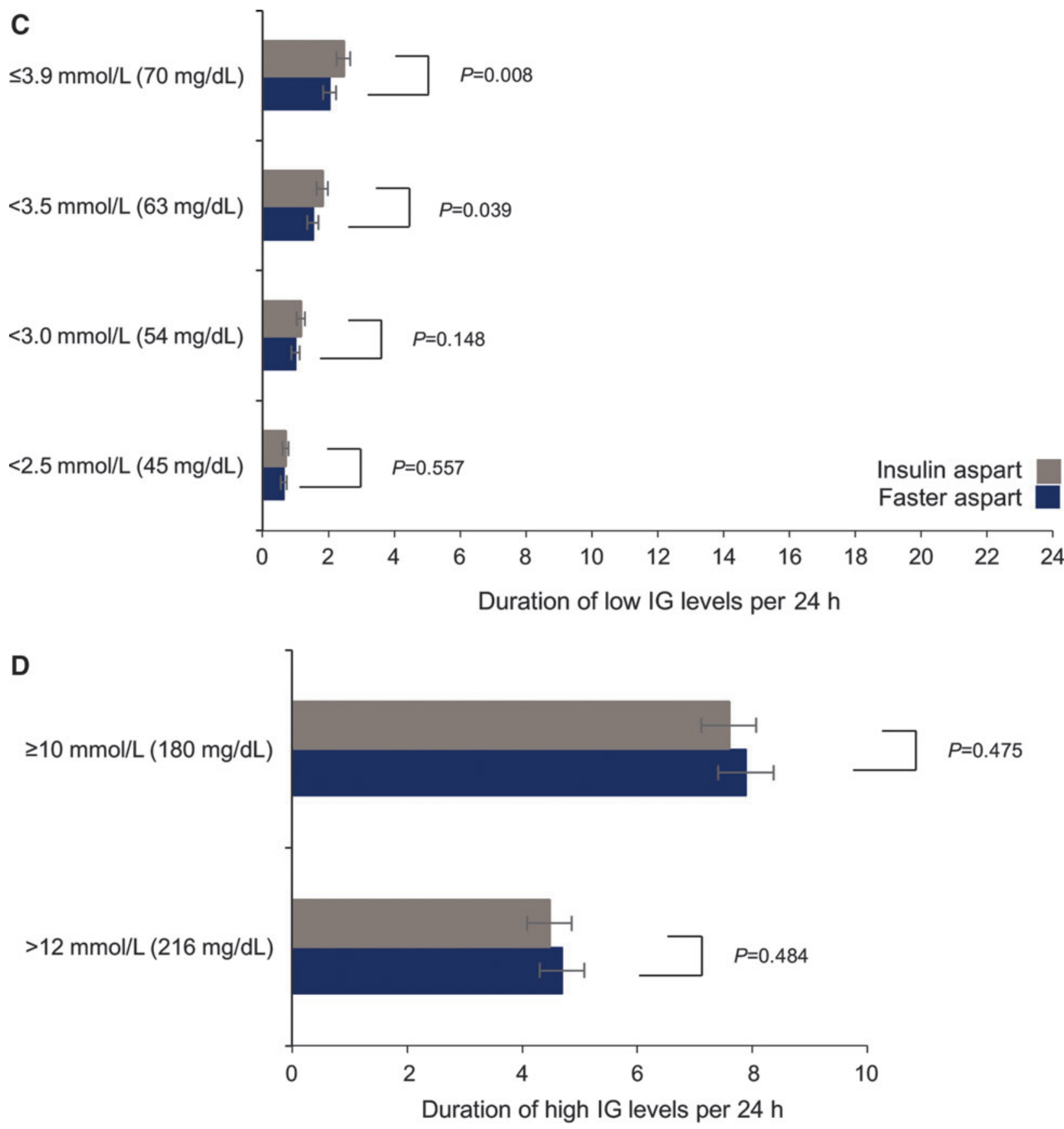

FIG. 2C and D panels (Continued).

In addition, the CGM data collected throughout the study indicated that there were improvements in PPG control after all meals. The greatest difference between faster aspart and IAsp in controlling IG over 2 weeks of treatment was observed after breakfast, where the IG increment over $1 \mathrm{~h}$ was 1.12 versus $2.04 \mathrm{mmol} / \mathrm{L}(20.19 \mathrm{mg} / \mathrm{dL}$ vs. $36.69 \mathrm{mg} / \mathrm{dL})$; there were no statistically significant differences after lunch or dinner. This observation is likely due, in part, to altered meal patterns and the tendency for subjects to consume snacks later in the day. Clinical experience shows that good PPG control after breakfast helps to set the stage for maintaining adequate glucose control over the rest of the day. ${ }^{8}$ The improvement in PPG control was achieved with less time spent with IG in the lower range $(\leq 3.9 \mathrm{mmol} / \mathrm{L}[70 \mathrm{mg} / \mathrm{dL}])$ during the day with faster aspart versus IAsp (with a difference of 25 min per day between treatments), which may help to improve control of postprandial hypoglycemia in a reallife setting. ${ }^{8}$

After 1 week, the SMPG profiles were similar for faster aspart and IAsp. Conversely, the SMPG profiles after 2 weeks were higher for faster aspart compared with IAsp. It should be noted, however, the mean IG results demonstrated no statistical significance in the difference between the two treatments, and this might more accurately reflect actual glycemic control than the limited observations achieved with the two 7-7-9-point SMPG profiles performed during the trial. 
The benefits of a faster onset of glucose-lowering action with faster aspart in CSII may be even greater if combined with CGM systems in both basal-bolus and hybrid or fully closed-loop settings. Although currently available closedloop systems are capable of responding safely to the different bolus-dosing scenarios that may occur in a patient's daily life, a 2014 study of 53 subjects with type 1 diabetes receiving RAIAs through CSII demonstrated that PPG control was compromised, with prolonged time periods spent with PPG levels $\geq 10.0 \mathrm{mmol} / \mathrm{L}(180 \mathrm{mg} / \mathrm{dL}){ }^{27}$

In the current study, faster aspart was well tolerated with a similar safety profile to IAsp and no new safety or tolerability issues were identified. The most common TEAEs reported in the trial were in order of frequency: hyperglycemia, headache, nasopharyngitis, and oropharyngeal pain. Due to the very frequent glucose monitoring and recording over the course of the study, an expectedly high frequency of hyper- and hypoglycemic events was observed with both faster aspart and IAsp.

The strengths of the present study include its doubleblinded design with a complete crossover, which enabled subjects to serve as their own controls, and that inclusion criteria required all subjects to use only a MiniMed Paradigm pump (which was widely used at the time of trial initiation). Furthermore, subjects had used one of the pumps selected for this investigation in the previous 6 months and were able to continue using their own pump during the study, thus removing the confounding factor of otherwise having to learn how to use a new device. A limitation of the study was its short duration and the standardized setting of the meal test. However, improvements in PPG with faster aspart versus IAsp were evident in the CGM recordings during daily meals, in which the carbohydrate and protein content of the meals was more representative of everyday practice.

The findings of this study in terms of greater early glucoselowering effect are in line with those recently reported by Heise et al., ${ }^{23}$ where faster aspart and IAsp were compared in a CSII setting. While compared with s.c. administration ${ }^{28}$ the differences in glucose-lowering effect between faster aspart and IAsp in a CSII setting appear to be more pronounced, ${ }^{23}$ the results of the ongoing Phase $3 \mathrm{~b}$ efficacy and safety pump trial with faster aspart will be important in terms of confirming the clinical utility of faster aspart over the longer term in a CSII setting.

In summary, faster aspart was well tolerated and associated with improvements in PPG compared with IAsp when in a CSII application. These findings could translate into clinical benefits in both CSII and future hybrid or fully closedloop systems.

\section{Acknowledgments}

The authors are grateful to the people who participated in this study, to Henrik Jarlov, MD, from Novo Nordisk A/S for his review and input to the article, and to Katharine A. Peregrìn, $\mathrm{PhD}$, from AXON Communications for medical writing and editorial assistance. This study was funded by Novo Nordisk A/S. B.W.B. was the principal investigator of this study; is the guarantor of this work and, as such, had full access to all data in the study; and takes responsibility for the integrity of the data and accuracy of the data analysis. All authors were involved in the preparation, editing, and approval of the manuscript in collaboration with Novo Nordisk. All authors meet the ICMJE criteria for authorship of this article. This publication was previously presented at the 75th Scientific Sessions of the American Diabetes Association, June 5-9, 2015, Boston, MA.

\section{Author Disclosure Statement}

B.W.B. reports grants and personal fees from Abbott, AstraZeneca, BD, Biodel, Boehringer Ingelheim, Dexcom, GSK, Insulet, Janssen, JDRF, Lexicon, Lilly, MannKind, Medtronic, NIH, Novo Nordisk, Pfizer, Sanofi, and Valeritas and holds shares with Aseko. L.H., S.T., and M.D. are employees of and hold shares with Novo Nordisk. J.J. has no competing financial interests.

\section{References}

1. Luijf YM, van Bon AC, Hoekstra JB, et al.: Premeal injection of rapid-acting insulin reduces postprandial glycemic excursions in type 1 diabetes. Diabetes Care 2010;33:2152-2155.

2. Lilly E: Humalog ${ }^{\circledR}$ (insulin lispro): Summary of Product Characteristics [article online]. www.ema.europa.eu/docs/en_ GB/document_library/EPAR_-_Product_Information/human/ 000088/WC500050332.pdf (accessed August 4, 2016).

3. Novo Nordisk. NovoRapid ${ }^{\circledR}$ (insulin aspart): Summary of Product Characteristics [article online]. www.ema.europa.eu/ docs/en_GB/document_library/EPAR_-_Product_Information/ human/000258/WC500030372.pdf (accessed August 4, 2016).

4. Sanofi-aventis. Apidra ${ }^{\circledR}$ (insulin glulisine): Summary of Product Characteristics [article online]. www.ema.europa.eu/docs/ en_GB/document_library/EPAR_-_Product_Information/ human/000557/WC500025250.pdf (accessed August 4, 2016).

5. Owens DR, Zinman B, Bolli GB: Insulins today and beyond. Lancet 2001;358:739-746.

6. Cobry E, McFann K, Messer L, et al.: Timing of meal insulin boluses to achieve optimal postprandial glycemic control in patients with type 1 diabetes. Diabetes Technol Ther 2010;12:173-177.

7. Scaramuzza AE, Iafusco D, Santoro L, et al.: Timing of bolus in children with type 1 diabetes using continuous subcutaneous insulin infusion (TiBoDi Study). Diabetes Technol Ther 2010;12:149-152.

8. Heinemann L, Muchmore DB: Ultrafast-acting insulins: state of the art. J Diabetes Sci Technol 2012;6:728-742.

9. Derosa G, Maffioli P, D'Angelo A, et al.: Effects of insulin therapy with continuous subcutaneous insulin infusion (CSII) in diabetic patients: comparison with multi-daily insulin injections therapy (MDI). Endocr J 2009;56:571-578.

10. Misso ML, Egberts KJ, Page M, et al.: Continuous subcutaneous insulin infusion (CSII) versus multiple insulin injections for type 1 diabetes mellitus. Cochrane Database Syst Rev 2010:CD005103.

11. Pickup JC, Sutton AJ: Severe hypoglycemia and glycemic control in Type 1 diabetes: meta-analysis of multiple daily insulin injections compared with continuous subcutaneous insulin infusion. Diabet Med 2008;25:765-774.

12. Equality 1 Study Group-Evaluation of QUALITY of Life and Costs in Diabetes Type 1; Nicolucci A, Maione A, Franciosi M, et al. Quality of life and treatment satisfaction in adults with Type 1 diabetes: a comparison between continuous subcutaneous insulin infusion and multiple daily injections. Diabet Med 2008;25:213-220.

13. Monami M, Lamanna C, Marchionni N, Mannucci E: Continuous subcutaneous insulin infusion versus multiple daily insulin injections in type 1 diabetes: a meta-analysis. Acta Diabetol 2010;47 (Suppl 1):77-81. 
14. Bode BW, Strange P: Efficacy, safety, and pump compatibility of insulin aspart used in continuous subcutaneous insulin infusion therapy in patients with type 1 diabetes. Diabetes Care 2001;24:69-72.

15. Lepore G, Tommaselli L: Subcutaneous insulin pump. In: Bruttomesso D, Grassi G, eds. Technological Advances in the Treatment of Type 1 Diabetes. Basel: Karger, 2015, Vol. 24, pp. 128-142.

16. Miller KM, Foster NC, Beck RW, et al.: Current state of type 1 diabetes treatment in the U.S.: updated data from the T1D Exchange clinic registry. Diabetes Care 2015;38: 971-978.

17. James ML, Green L, Amiel SA, et al.: Evaluation of the effect of carbohydrate intake on postprandial glucose in patients with type 1 diabetes treated with insulin pumps. J Diabetes Sci Technol 2016;10(6):1287-1293.

18. El-Khatib FH, Russell SJ, Nathan DM, et al.: A bihormonal closed-loop artificial pancreas for type 1 diabetes. Sci Transl Med 2010;2:27ra27.

19. Luijf YM, DeVries JH, Zwinderman K, et al.: Day and night closed-loop control in adults with type 1 diabetes: a comparison of two closed-loop algorithms driving continuous subcutaneous insulin infusion versus patient selfmanagement. Diabetes Care 2013;36:3882-3887.

20. Russell SJ, El-Khatib FH, Nathan DM, et al.: Blood glucose control in type 1 diabetes with a bihormonal bionic endocrine pancreas. Diabetes Care 2012;35:2148-2155.

21. Food and Drug Administration (FDA). Inactive Ingredient Search for Approved Drug Products [database online], April 2016. www.accessdata.fda.gov/scripts/cder/iig/getiig WEB.cfm (accessed August 4, 2016).

22. Buckley ST, Kildegaard J, Høiberg-Nielsen R, et al.: Mechanistic analysis into the mode of action of niacinamide in faster-acting insulin aspart. Diabetes Technol Ther 2016:A291.

23. Heise T, Zijlstra E, Nosek L, Rikte T, et al.: Pharmacological properties of faster-acting insulin aspart versus insulin aspart in patients with type 1 diabetes using continuous subcutaneous insulin infusion: a randomised, double-blind, crossover trial. Diabetes Obes Metab 2016; doi:10.1111/ dom. 12803.

24. World Medical Association. WMA Declaration of Helsinki: Ethical Principles for Medical Research Involving Human Subjects-Last amended by the 64th WMA General Assembly, Fortaleza 2013. www.wma.net/en/30publications/ 10policies/b3 (accessed August 4, 2016).

25. International Conference on Harmonisation of Technical Requirements for Registration of Pharmaceuticals for Human Use. ICH Harmonised Tripartite Guideline. Guideline for Good Clinical Practice. E6(R1) 10 June 1996. www.ema .europa.eu/docs/en_GB/document_library/Scientific_guideline/ 2009/09/WC500002874.pdf (accessed August 4, 2016).

26. Seaquist ER, Anderson J, Childs B, et al.: Hypoglycemia and diabetes: a report of a workgroup of the American Diabetes Association and the Endocrine Society. Diabetes Care 2013;36:1384-1395.

27. Chase HP, Doyle FJ III, Zisser H, et al.: Multicenter closedloop/hybrid meal bolus insulin delivery with type 1 diabetes. Diabetes Technol Ther 2014;16:623-632.

28. Heise T, Pieber TR, Danne T, et al.: Faster onset and greater early exposure and glucose lowering effect with faster-acting insulin aspart versus insulin aspart: a pooled analysis in subjects with type 1 diabetes. Diabetes 2016;65 (Suppl 1):A239.

Address correspondence to:

Bruce W. Bode, MD, FACE

Atlanta Diabetes Associates

1800 Howell Mill Road NW, Suite 450

Atlanta, GA 30318

E-mail: bbode001@aol.com 